Arab Univ. J. Agric. Sci., Ain Shams Univ., Cairo, Egypt

28(1), 155-164, 2020

Website: http://ajs.journals.ekb.eg

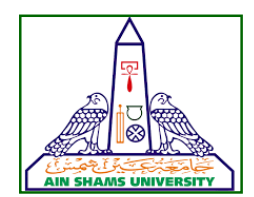

155

\title{
AN ANALYSIS OF HOUSEHOLD DEMAND FOR FOOD AWAY FROM HOME (FAFH) IN RIYADH, SAUDI ARABIA: A RIGHT-LEFT TRUNCATED GENERALIZED POISSON REGRESSION MODEL
}

[10]

\author{
Alnafissa* M.A., Alderiny M.M., Kotb A.A. and Ahmed Sh.B. \\ Agricultural Economics Dept., College of Food and Agricultural Sciences, King Saudi Univ., \\ P.O. Box 2460, Riyadh 11451, Kingdom of Saudi Arabian
}

*Corresponding author: malnafissa@ksu.edu.sa

Accepted 18 May, 2020

\section{ABSTRACT}

This study analyzed the determinants of household demand for food away from home (FAFH) in Riyadh, Saudi Arabia. Truncated generalized Poisson regression (TGPR) and truncated standard Poisson regression (TSPR) was applied to data from a random sample of 101 families. Maximum likelihood was used to obtain parameter estimates for these two models. TGPR was found to be optimal and appropriate for the analysis of demand data. Both income and number of household members had a significant positive effect, which is consistent with economic logic and reality in Saudi society. Price and taste also had positive effects on FAFH demand. Household income as an economic variable has a significant positive effect on the number of times that a household dines out during the month. When income increases by one thousand Saudi riyals, the demand will increase by $11 \%$, which is consistent with economic logic. Household income as a quantitative economic variable and the number of household members as a quantitative demographic variable are the most important variables in household demand for FAFH. However, the effect of income is more significant than that of the number of household members. As this study investigated the impact of socio-economic and demographic factors on food away from home (FAFH) demand in Riyadh such as household income, number of household members, education level, prices and cleanness of restaurant, and taste of food. Still there are other variables could be used as potential variables could affect FAFH demand in Saudi Arabia in future research such as the change in
\end{abstract}

number of working women which there is shift in the number of female workers recently. The future studies could look at the differences in socioeconomic between consumers for different types of restaurants such as traditional, fast food, fish, and luxury restaurants. Due to the high demand for restaurant meals, officials should tighten the health control and close restaurants that do not comply with health requirements as well security and safety requirements. Restaurants should pay attention to improving the quality of meals and offering them at affordable prices to consumers.

Keywords: Demand, Food away from home (FAFH), Food consumption, Generalized Poisson, Maximum likelihood.

\section{INTRODUCTION}

The behavior of Saudi families has changed from gathering around a table of food that is prepared at home to exhibiting diverse desires and preferences for eating food away from home (FAFH). Now, Saudi families spend part of their income on FAFH. There are many restaurants in Saudi Arabia for its large population, and these vary in the provision of different meals such as fast food, luxury, and traditional food. Recently, there has been an increase in the number of international restaurants in the Saudi market due to the large demand and high volume of profit. There has also been a noticeable increase in restaurant delivery services, for which consumers connect to restaurants directly or through other intermediaries, and multiple electronic applications are used for this purpose. The number of enterprises providing food 
and beverage services in Saudi Arabia increased from about 63,000 in 2010 to about 75,900 in 2017. The revenues of these restaurants increased from about 27.5 million Saudi riyals in 2005 to about 34 million Saudi riyals in 2010 to more than 50 million Saudi riyals in 2017 (General Authority for Statistics, 2007-2017).

The increase in the restaurants' revenue could evidence the change in consumption patterns due to different reasons such as longer working hours for individuals of both sexes as well as the frequency of restaurants being a source of entertainment and a place to meet household and friends. In addition, the increase in population and income as well the different ways in which restaurants attract customers could be related to the increase in total FAFH expenditure.

Dining out is a global phenomenon, not only at the local Saudi level. As such, many studies have dealt with this phenomenon in the United States (Liu et al 2013 and Richards \& Mancino, 2013), Slovakia (Cupak et al 2016), Malaysia (Tan, 2010), Mexico (Langellier, 2015), Korea (Kim et al 2014), Brazil (Queiroz and Coelho, 2018), the United Kingdom (Adams et al 2015), and China (Liu et al 2015). The literature discusses different aspects related to FAFH, such as factors of effect, the association with the health situation, and demand elasticity.

There are different factors that can relate to the consumption of FAFH: namely, income, education, and working hours (Liu et al 2013, Langellier, 2015 and Cupak et al 2016). In addition, FAFH demand could be effected by the increase in the number of women workers and the change in household structure such as the number of kids (Queiroz \& Coelho, 2018 and Cupak et al 2016). The effect of these factors for the household demand on FAFH could also be changed regard the types of meal whether it's breakfast, lunch, dinner, or snack (Mutlu and Gracia, 2006). Regarding food quality and health, the previous literature examined the impact of consumed FAFH on diet quality and found that in addition to the increase in daily caloric intake, there has been a reduced consumption of whole grains, vegetables, and sodium (Todd et al 2010 and Llanaj et al 2018) and an increased consumption of saturated and solid fat, alcohol, and added sugar. The impact of consuming FAFH points to a positive relationship between overweight/obesity, fat, body mass index (BMI), and waist circumference (Thompson et al 2004, Langellier, 2015 and Kim et al 2014), and this impact is higher in fast food restaurants (Larson,
2011). Studies have found that FAFH is a luxury good that is elastic in relation to increases in food prices, and consumers are willing to substitute it for eating at home (Langellier, 2015 and Cupak et al 2016).

As previously mentioned, the number of restaurants in Saudi Arabia is growing, and there is an increasing demand for FAFH. Although the literature has investigated the effects of socio-economic factors on demand in several countries, there is a lack of studies on the demand for restaurant meals in Saudi Arabia. Therefore, this study aims to analyze the factors affecting household demand for FAFH in Riyadh, which is the capital city in the country.

The study is organized as follows. Section 2 describes the methodology, which includes a right and left truncated generalized Poisson regression (TGPR) model, a parameter estimation using maximum likelihood, statistical tests for goodness of fit, and significance tests for regression coefficients including the dispersion parameter. Section 3 includes the sources of data that describe the number of times that families eat restaurant meals each month and analyzes as dependent variables the factors that affect this number. In Section 4, we present the analysis of the results and discussion that relates to the maximum likelihood estimates for the parameters of the TGPR model and compare those with the parameter estimates of the truncated standard Poisson regression (TSPR) model. Sections 5 and 6 present the conclusions and recommendations respectively.

\section{MATERIAL AND METHODS}

The objective of this research is to analyze the determinants of household demand for FAFH. Household demand for FAFH is measured by the number of times that a household consumes restaurant meals each month, which is count data, and the variables that could affect the number of visits to restaurants in Riyadh, Saudi Arabia. Then, we identify the importance of these variables. As such, the appropriate model to analyze the data is the Poisson regression model, which is used when dependent variables are count data (Greene, 2003).

In many applications, the mean of the count data does not equal variance when there is overdispersion or under-dispersion. Moreover, the distribution of these count data is truncated from the right side as well as the left side; therefore, the standard Poisson regression (SPR) model is not 
appropriate to study the relation between the dependent variables and the set of explanatory variables. This study will introduce a right-left TGPR model as an appropriate model to analyze the truncated count data.

\section{Right-Left TGPR Model}

By assuming that the count dependent variable $Y$ represents the number of times that a Saudi household consumes restaurant meals each month, $Y$ is a generalized Poisson random variable affected by a set of explanatory variables $\left(x_{1}\right.$, $\left.x_{2}, \ldots x_{p-1}\right)$. The generalized Poisson regression (GPR) model introduced by Famoye (1993) represents the probability function of the $Y_{i}$ conditional on a vector of explanatory variables $x_{i}=\left(1, x_{i 1}\right.$, $\left.x_{i 2}, \ldots x_{i, p-1}\right)^{\prime}$ and is written as follows:

$$
\begin{aligned}
& \pi\left(y_{i} \mid \boldsymbol{x}_{i}, \boldsymbol{\beta}, \alpha\right)=\operatorname{pr}\left(Y_{i}=y_{i} \mid \boldsymbol{x}_{i}, \boldsymbol{\beta}, \alpha\right)=\left(\frac{\mu_{i}}{1+\alpha \mu_{i}}\right)^{y_{i}-1} \\
& \exp \left(\frac{-\mu_{i}\left(1+\alpha y_{i}\right)}{\left(1+\alpha \mu_{i}\right)}\right) \frac{1}{y_{i} !}, y_{i} 0,1, \ldots, i=1,2, \ldots, n
\end{aligned}
$$

where conditional mean and variance of $Y_{i}$ on $x_{i}=$ $\left(1, x_{i 1}, x_{i 2}, \ldots x_{i, p-1}\right)^{\prime}$ are given by $E\left(Y_{i} \mid \boldsymbol{x}_{i}\right)=\mu_{i}$ and $\operatorname{Var}\left(Y_{i} \mid \boldsymbol{X}_{i}\right)=\mu_{i}\left(1+\alpha \mu_{i}\right)^{2}$. The mean of the dependent variable is related to the explanatory variables through the exponential link function $E\left(Y_{i} / \boldsymbol{x}_{i}\right)=\mu_{i}$ $=\exp \left(\boldsymbol{x}_{i}^{\prime} \boldsymbol{\beta}\right)$, where $\boldsymbol{\beta}=\left(\beta_{0}, \beta_{1}, \beta_{2}, \ldots, \beta_{\mathrm{p}-1}\right)^{\prime}$ is a $\boldsymbol{p}$ dimensional vector of regression parameters, and $\alpha$ is the dispersion parameter. When $\alpha=0$, the probability function of the generalized Poisson random variable in (1) reduces to the standard Poisson $(S P)$ probability function. The positive value of $\alpha$ in (1) indicates the over-dispersion of the distribution, whereas the negative value of $\alpha$ indicates the under-dispersion. To select the right type of Poisson regression model, it is necessary to check for a dispersion problem in the data. From the moment estimates $\hat{\mu}=\sqrt{\bar{Y}^{3} / S_{Y}^{2}}$ and $\hat{\alpha}=1-$ $\sqrt{\bar{Y} / S_{Y}^{2}}$ that are given by Consul and Jain (1973), we can explore the type of Poisson regression model where $\bar{Y}$ and $S_{Y}^{2}$ denote the sample mean and the variance, respectively.

If the number of times that a household dines in a restaurant during the month has possible values $Y_{i}=l, l+1, \ldots, u$, model (1) under truncated values $Y_{i}<l, Y_{i}>u$, represents the conditional distribution $\pi\left(y_{i} \mid l \leq y_{i} \leq u, \boldsymbol{x}_{i}, \boldsymbol{\beta}, \alpha\right)$ and is written as follows (Greene, 2003):

$$
\begin{gathered}
\pi\left(y_{i} \mid l \leq y_{i} \leq u, \boldsymbol{x}_{i}, \boldsymbol{\beta}, \alpha\right)=\operatorname{pr}\left(\left(Y_{i}=y_{i} \mid l \leq y_{i} \leq u\right)\right. \\
=\frac{\pi\left(y_{i} \mid \boldsymbol{x}_{i, \boldsymbol{\beta}}, \alpha\right)}{\sum_{j-l}^{u} \pi\left(j \mid \boldsymbol{x}_{i, \boldsymbol{\beta}}, \alpha\right)}, y_{i}=l, l+1, \ldots, u
\end{gathered}
$$

\section{Maximum Likelihood Estimation}

Maximum likelihood can be used to estimate the unknown parameters of the TGPR as shown in model (2). The log-likelihood function $L L(\beta, \alpha)$ is denoted as follows:

$$
\begin{gathered}
L L(\boldsymbol{\beta}, \alpha)=\sum_{i=1}^{n} \log _{e}\left(\left(y_{i} \mid l \leq y_{i} \leq u, \boldsymbol{x}_{i}, \boldsymbol{\beta}, \alpha\right)\right. \\
=\sum_{i=1}^{n}\left[y_{i} \log _{e}\left(\frac{\mu_{i}}{1+\alpha \mu_{i}}\right)+\left(y_{i}-1\right) \log _{e}\left(1+\alpha y_{i}\right)\right. \\
\left.-\frac{\mu_{i}\left(1+\alpha y_{i}\right)}{\left(1+\alpha \mu_{i}\right)}-\log _{e}\left(y_{i} !\right)-\log _{e}\left(C D F_{(l, u)}\right)\right]
\end{gathered}
$$

where $C D F_{(l, u)}=\sum_{j=1}^{u}\left(\pi\left(j \mid x_{i}, \boldsymbol{\beta}, \alpha\right)\right)$

The maximum likelihood estimation of the model parameters are the values of $\alpha$ and vector $\boldsymbol{\beta}$ that maximize $L L(\boldsymbol{\beta}, \boldsymbol{\alpha})$ in (3) and can be obtained from solving equations

$$
\begin{aligned}
& \frac{\partial L L(\beta, \alpha)}{\partial \alpha}=0=\sum_{i=1}^{n}\left[\frac{\partial \log _{e}\left[\pi\left(y_{i} \mid \boldsymbol{x}_{i}, \boldsymbol{\beta}, \alpha\right)\right]}{\partial \alpha}-\frac{\left(\frac{\partial C D F_{(l, u)}}{\partial \alpha}\right)}{C D F_{(l, u)}}\right] \\
& \frac{\partial L L(\beta, \alpha)}{\partial \beta_{k}}=0=\sum_{i=1}^{n}\left[\frac{\partial \log _{e}\left[\pi\left(y_{i} \mid \boldsymbol{x}_{i}, \boldsymbol{\beta}, \alpha\right)\right]}{\partial \beta_{k}}-\frac{\left(\frac{\partial C D F_{(l, u)}}{\partial \beta_{k}}\right)}{C D F_{(l, u)}}\right]
\end{aligned}
$$

$k=0,1,2, \ldots, p-1$

Where

$\frac{\partial \log _{e}\left[\pi\left(y_{i} \mid \boldsymbol{x}_{i}, \boldsymbol{\beta}, \alpha\right)\right]}{\partial \alpha}=\frac{y_{i}\left(y_{i}-1\right)}{\left(1+\alpha y_{i}\right)}-\frac{\mu\left(y_{i}-\mu_{i}\right)}{\left(1+\alpha \mu_{i}\right)^{2}}-\frac{\mu_{i} y_{i}}{\left(1+\alpha \mu_{i}\right)^{\prime}}$

$\frac{\partial \log _{e}\left[\pi\left(y_{i} \mid \boldsymbol{x}_{i}, \boldsymbol{\beta}, \alpha\right)\right]}{\partial \beta_{k}}=\frac{x_{k} y_{i}}{\left(1+\alpha y_{i}\right)}-\frac{\mu x_{k}\left(1+\alpha y_{i}\right)}{\left(1+\alpha \mu_{i}\right)^{2}}=\frac{x_{k}\left(y_{i}-\mu_{i}\right)}{\left(1+\alpha \mu_{i}\right)^{2}}$,

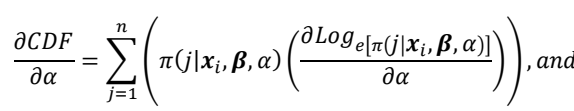

$\frac{\partial C D F}{\partial \alpha \beta_{k}}=\sum_{j=1}^{n}\left(\pi\left(j \mid \boldsymbol{x}_{i}, \boldsymbol{\beta}, \alpha\right)\left(\frac{\partial \log _{e\left[\pi\left(j \mid \boldsymbol{x}_{i}, \boldsymbol{\beta}, \alpha\right)\right]}}{\partial \alpha}\right)\right), k$

$=0,1,2, \ldots, p-1$ 
The likelihood in equation (3) is non-linear in parameters $\alpha$ and $\beta=\left(\beta_{0}, \beta_{1}, \beta_{2}, \ldots, \beta_{p-1}\right)^{\prime}$. Statistical analysis software (SAS9.2, 2008) can be used to carry out the Newton-Raphson method for solving these equations simultaneously, where the estimate of parameters in iteration $r$ is denoted as follows:

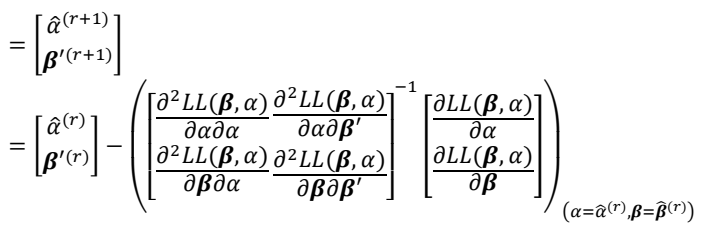

The initial estimate $\hat{\alpha}^{(0)}, \boldsymbol{\beta}^{(0)} \hat{\alpha}^{(0)}, \boldsymbol{\beta}^{(0)}$ may be taken as the corresponding final estimates of $\alpha$ and $\boldsymbol{\beta}$ from fitting a GPR model to the data.

Fisher's information matrix $\mathbf{I}(\boldsymbol{\alpha}, \boldsymbol{\beta})$ can be obtained by taking the expectations of minus the second derivatives. The inverse of the $I(\alpha, \beta)$ matrix will provide the variance of the maximum likelihood estimates. The variance of the maximum likelihood estimates can also be obtained from Hessian matrix $\mathbf{H}$, which is a square matrix of order $p$. The entries of the Hessian matrix are denoted by the second order partial derivatives of (3) and given by:

$\mathbf{H}_{(\alpha, \boldsymbol{\beta})}=\left[\begin{array}{l}\mathbf{H}_{11} \mathbf{H}_{12} \\ \mathbf{H}_{21} \mathbf{H}_{22}\end{array}\right]=\left[\begin{array}{ll}\frac{\partial^{2} \operatorname{LL}(\boldsymbol{\beta}, \alpha)}{\partial \alpha \partial \alpha} & \frac{\partial^{2} \operatorname{LL}(\boldsymbol{\beta}, \alpha)}{\partial \alpha \partial \beta} \\ \frac{\partial^{2} \operatorname{LL}(\boldsymbol{\beta}, \boldsymbol{\alpha})}{\partial \boldsymbol{\beta} \partial \alpha} & \frac{\partial^{2} \operatorname{LL}(\boldsymbol{\beta}, \boldsymbol{\alpha})}{\partial \boldsymbol{\beta} \boldsymbol{\beta} \boldsymbol{\beta} \prime}\end{array}\right]$

where $S A S$ outputs include $\mathbf{H}_{(\widehat{\alpha}, \widehat{\boldsymbol{\beta}})}$, which represents the Hessian matrix evaluated at maximum likelihood estimates. Then the variance-covariance matrix of estimates is denoted by $\mathbf{S}^{2}(\widehat{\alpha}, \widehat{\boldsymbol{\beta}})=$ $\left(-\mathbf{H}_{(\widehat{\alpha}, \widehat{\boldsymbol{\beta}})}\right)^{-1}$.

\section{Statistical Inference}

After obtaining the maximum likelihood estimates, all statistical hypothesis tests that achieve the objectives of the research can be conducted as follows. To test the goodness-of-fit of the right-left (TGPR) model, we can apply the likelihood ratio to test the null and alternative hypothesis:

$H_{0}: \beta_{1}=\beta_{2}=\cdots=\beta_{p-1}=0$ vs. $H_{1}:$ at least one of $\beta_{k} \neq$

$0, k=1,2, \ldots, p-1$

and the likelihood ratio to test statistics as
$L R=-2\left(L L\left(\widehat{\boldsymbol{\beta}}, \hat{\alpha} \mid H_{0}\right)-L L\left(\widehat{\boldsymbol{\beta}}, \hat{\alpha} \mid H_{1}\right)\right)$ where $L L\left(\widehat{\boldsymbol{\beta}}, \hat{\alpha} \mid H_{0}\right)$ and $L L\left(\widehat{\boldsymbol{\beta}}, \hat{\alpha} \mid H_{1}\right)$ are, respectively, the maximum values of log-likelihood function under restrictions $\left(\boldsymbol{H}_{0}\right)$ and unrestrictions $\left(\boldsymbol{H}_{1}\right)$ on coefficients. Under the null hypothesis $\left(\boldsymbol{H}_{0}\right)$, the test statistics $L R$ in (8) follow a chi-square distribution $\chi_{(p-1)}^{2}$ with $(p-1)$ degrees of freedom.

To test the null hypothesis $\boldsymbol{H}_{0}$ : $\boldsymbol{\alpha}=0$ to determine the type of Poisson regression model, if $\boldsymbol{H}_{\boldsymbol{0}}$ : $\alpha=0$ is rejected, the (TGPR) model is preferred rather than the (TSPR) model. To test the null hypothesis $\boldsymbol{H}_{0}: \boldsymbol{\beta}_{\mathrm{k}}=0, k=0,1, \ldots, p-1$ to determine the explanatory variables that have a significant effect on household demand for restaurant meals, which is measured by the number of times a household eats in a restaurant, if $\boldsymbol{H}_{\boldsymbol{0}}: \boldsymbol{\beta}_{\mathrm{k}}=0$ is rejected, the explanatory variable $\left(X_{k}\right)$ has a significant effect. The test statistics for $\boldsymbol{H}_{0}: \boldsymbol{\alpha}=0$ and $\boldsymbol{H}_{\boldsymbol{0}}: \boldsymbol{\beta}_{\mathrm{k}}=0$ are $Z_{\alpha}=\hat{\alpha} / S_{\widehat{\alpha}}$ and $Z_{\beta_{k}}=\hat{\beta} / S_{\widehat{\beta}_{k}}$, respectively; under null hypothesis $\boldsymbol{H}_{\boldsymbol{0}}$, test statistics $\boldsymbol{Z}$ has approximately standard normal distribution and $S_{(\ldots)}$ standard error of parameter estimation.

Akaike information criterion (AIC) can be applied to compare the (TSPR) model with the (TGPR) model, and the model that corresponds to the minimum value of (AIC) may be selected as the optimal model to analyze the data. The (AIC) value of the model is written as follows (Akaike, 1973):

AIC $=2 q-2 L L($ estimates $)$

Where $q$ denotes the number of estimated parameters in the model and LL(estimates) is the maximum value of the log likelihood function for the model that enters comparison.

In SAS program, the statement, "PROC NLP" nonlinear procedure offers a set of optimization techniques for maximizing log-likelihood function, as well all request results for analysis.

\section{Data and descriptions of demand for restau- rant meals}

The data of the variables under study were collected through an electronic survey in which 101 surveys from Saudi households were analyzed. The surveys were collected from April 8 to 9, 2018. The research vocabulary (family in the city of

Riyadh) is similar in terms of the standard of living and the culture of family demand for fast food to some extent, and then this sample represents the community well represented, as the sample size 

Arabia: a right-left truncated generalized poisson regression model

101 is sufficient number to beautify all statistical analyzes. It allows specifying the sample size, as the minimum sample size was calculated under the assumption that the population size is large, and the desired margin of error is $10 \%$ when estimating a $95 \%$ confidence interval for the percentage in the community, and it was found that its value is approximately 96 , so the size 101 achieves the minimum Required for the sample size. The data of the dependent variable (Y) include the number of times that the Saudi household eats a restaurant meals during the month as a variable, and has a Poisson distribution, while the independent variables data include monthly household income by thousand Saudi riyals $\left(X_{1}\right)$, number of household members $\left(X_{2}\right)$, education level of the household leader $\left(X_{3}\right)$, and household preference to eat in restaurants $\left(X_{4}\right)$. The education level of the household leader as the ordinal variable has four levels denoted by values $\left(X_{3}=1,2,3,4\right)$ according to level (primary, middle, secondary, and academic), respectively; household preference to eat in restaurants as a category variable has two groups denoted by one dummy variable $\left(X_{4}=1\right.$ if household prefer, $X_{4}=0$ if household does not prefer), and the attractions for eating in a restaurant as another category variable includes three groups (good price, delicious taste, cleanliness) denoted by two dummy variables as:

$X_{51}=\left\{\begin{array}{c}1 \text { if family selects good price } \\ 0 \text { otherwise }\end{array}\right.$

$X_{52}=\left\{\begin{array}{c}1 \text { if family selects delicious taste } \\ 0 \text { otherwise }\end{array}\right.$

Table 1 presents the means and the standard deviations of the independent quantitative variables at each value of the dependent variable, while Table 2 shows the counts and percentages for the levels of independent qualitative variables as well the mean and standard deviation of the dependent variable in each level.
In Table 1, we note that the KolmogorovSmirnov test statistics and $p$ value $(K . S Z, p r)$ are 1.051 and 0.219 , respectively, which means that the number of times a household eats restaurant meals during the month has a Poisson distribution. The estimation of the mean and variance of the dependent variable are $(\bar{Y}=2.257)$ and $\left(S_{Y}^{2}\right)=$ 1.073, respectively, revealing the under-dispersion where moment estimation is $\left(\hat{\alpha}_{\text {mom }}=-0.45\right)$. Additionally, there is a positive correlation between number of times consuming FAFH and the average of both household income and the number of household members.

Table 1. Means and standard deviations of quantitative variables

\begin{tabular}{|c|c|c|c|c|c|}
\hline \multirow{2}{*}{} & \multirow{2}{*}{ (Count, \%) } & \multicolumn{2}{|c|}{$\begin{array}{c}\text { Household } \\
\text { income }\end{array}$} & \multicolumn{2}{c|}{$\begin{array}{c}\text { Number of house- } \\
\text { hold members }\end{array}$} \\
\cline { 3 - 6 } & & Mean & SD & Mean & SD \\
\hline 1 & $(29,28.71)$ & 7.966 & 2.368 & 4.724 & 1.334 \\
2 & $(32,31.68)$ & 8.375 & 2.406 & 4.969 & 1.356 \\
3 & $(25,24.75)$ & 8.760 & 2.260 & 5.280 & 0.980 \\
4 & $(15,14.85)$ & 10.333 & 0.976 & 5.867 & 1.356 \\
(K.S Z, pr) & $(1.051$, & 8.644 & 2.305 & 5.109 & 1.303 \\
& $0.219)$ & & & & \\
(Mean, & $(2.257$, & & & & \\
Variance) & $1.073)$ & & & & \\
\hline
\end{tabular}

Source: computed from sample data

In Table 2, it is noted that the percentages of the education levels in the sample are different, and the largest percentage $(54.5 \%)$ is in the academic level. However, the mean of times number that household consumes FAFH for these levels are close together. In addition, the percentages of the levels of household preference to eat FAFH are different, where the percentage of approval for eating in restaurants and the mean of the number of times that household consumes FAFH $(66.3 \%$ and 2.46 , respectively) are large. Considering the factors of attraction for eating FAFH, the percentages of these factors are different. The percentage of families who eat FAFH because of the taste and the mean of number of times the household consumes FAFH per month are $50.5 \%$ and 2.61 , respectively. 
Table 2. Counts and percentages for qualitative variable levels as the means and standard deviations of dependent variables within levels

\begin{tabular}{|c|c|c|c|c|}
\hline \multicolumn{2}{|c|}{$\begin{array}{c}\text { Independent Qualitative } \\
\text { Variables }\end{array}$} & \multirow{2}{*}{$\frac{\text { (Count, \%) }}{(8,7.9)}$} & \multirow{2}{*}{$\begin{array}{c}\text { Mean } \\
1.75\end{array}$} & \multirow{2}{*}{$\begin{array}{c}\text { SD } \\
1.165\end{array}$} \\
\hline Education level & Primary & & & \\
\hline & Middle & $(11,10.9)$ & 2.55 & 1.036 \\
\hline & Secondary & $(27,26.7)$ & 2.19 & .962 \\
\hline & Academic & $(55,54.5)$ & 2.31 & 1.052 \\
\hline \multirow{2}{*}{$\begin{array}{c}\text { Household } \\
\text { preference for } \\
\text { eating out }\end{array}$} & No & $(34,33.7)$ & 1.85 & .892 \\
\hline & Yes & $(67,66.3)$ & 2.46 & 1.049 \\
\hline \multirow{3}{*}{$\begin{array}{l}\text { Attractions for } \\
\text { eating at res- } \\
\text { taurants }\end{array}$} & Good price & $(13,12.9)$ & 2.54 & .776 \\
\hline & Delicious taste & $(51,50.5)$ & 2.61 & 1.078 \\
\hline & Cleanliness & $(37,36.6)$ & 1.68 & .784 \\
\hline
\end{tabular}

Source: computed from sample data

\section{RESULTS AND DISCUSSION}

As seen in Table 1, the number of times that a household consumes FAFH during the month as a dependent variable takes the values $(Y=1,2,3,4)$ . This variable is expressed by two truncated Poisson regression models: TSPR and TGPR that showed in equation (2) in the situation $(l=1, u=$ 4).

Table 3 shows the results of maximum likelihood estimates of parameters in the TSPR and the TGPR models. We note that the estimated value of dispersion parameter $\alpha$ in the TGPR model is 0.141 , which indicates the under-dispersion property in the distribution of dependent variable data as well the $p$ value $\operatorname{Pr}(>|z|)=0.0$. This is less than 0.05 , which indicates that the null hypothesis $H_{0}$ : $\alpha=0$ could be rejected at the significance level of $5 \%$. By comparing the TSPR model with the TGPR model, we note that the log likelihood function in the TSPR model $\left(L L_{u}\left(H_{1}\right)=-122.505\right)$ is less than the log likelihood function in the TGPR model $\left(L L_{u}\left(H_{1}\right)=-116.047\right)$, and the standard error of coefficient estimates in the TGPR model is less than the standard error in the TSPR model, so the coefficient estimates of the TGPR model are more efficient. The AIC value in the case of application model TGPR is 248.09 , which is less than the AIC value in the TSPR model (286.96), so the TGPR model should be selected as the optimal model to analyze the determinants of household demand for restaurant meals in Riyadh.

Household income as an economic variable has a significant positive effect on the number of times that a household dines out during the month. When income increases by one thousand Saudi riyals, the demand will increase by $11 \%$, which is consistent with economic logic. In addition, the number of household members as a demographic variable has a significant positive effect on household demand for restaurant meals. When a household increases by one member, the demand increases by $16.4 \%$. Both good price and delicious taste as factors of attraction for the household to eat FAFH have a significant positive effect, but delicious taste is more significant.

Education level in this analysis take as ordinal variable which as mentioned above the four level of education (primary, middle, secondary, and academic) is take number between 1 for low education level and 4 for high education level. The result of analysis find there is no significant for the impact of education level on FAFH demand. This output could be explained by low cost of live in Saudi Arabia and there are different options of restaurants which this study does not distinguish between them. 
Table 3. Results of maximum likelihood estimates for TSGR and TGPR parameters

\begin{tabular}{|c|c|c|c|c|c|c|c|c|c|}
\hline \multirow[b]{2}{*}{ Variable } & \multirow[b]{2}{*}{ Parameter } & \multicolumn{4}{|c|}{ TSPR } & \multicolumn{4}{|c|}{ TGPR } \\
\hline & & Estimates & $\begin{array}{l}\text { Std. } \\
\text { Error }\end{array}$ & $\mathbf{Z}$ & $\operatorname{Pr}$ & Estimates & $\begin{array}{l}\text { Std. } \\
\text { Error }\end{array}$ & $\mathbf{z}$ & $\operatorname{Pr}$ \\
\hline \multicolumn{2}{|c|}{ Dispersion parameters } & & & & & -0.141 & 0.035 & -4.035 & 0.000 \\
\hline \multicolumn{2}{|c|}{ Constant } & -2.799 & 0.699 & -4.006 & 0.000 & -1.060 & 0.448 & -2.367 & 0.020 \\
\hline \multicolumn{2}{|c|}{ Household income } & 0.110 & 0.049 & 2.267 & 0.026 & 0.088 & 0.030 & 2.932 & 0.004 \\
\hline \multicolumn{2}{|c|}{ Household members } & 0.164 & 0.084 & 1.964 & 0.052 & 0.111 & 0.048 & 2.333 & 0.022 \\
\hline \multicolumn{2}{|c|}{ Education level } & 0.052 & 0.117 & 0.442 & 0.660 & -0.002 & 0.065 & -0.034 & 0.973 \\
\hline \multicolumn{2}{|c|}{$\begin{array}{c}\text { Preference yes for } \\
N o^{(r)} \text { restaurants }\end{array}$} & 0.183 & 0.245 & 0.749 & 0.455 & 0.071 & 0.154 & 0.458 & 0.648 \\
\hline \multirow{2}{*}{\multicolumn{2}{|c|}{$\begin{array}{l}\text { Attraction } P r . \\
\text { reasons Taste Clean }\end{array}$}} & 0.756 & 0.348 & 2.174 & 0.032 & 0.613 & 0.209 & 2.936 & 0.004 \\
\hline & & 0.728 & 0.248 & 2.935 & 0.004 & 0.593 & 0.179 & 3.320 & 0.001 \\
\hline \multicolumn{2}{|c|}{$L L_{U}\left(H_{1}\right)$} & \multicolumn{4}{|c|}{-122.505} & \multicolumn{4}{|c|}{-116.047} \\
\hline \multicolumn{2}{|c|}{$L L_{R}\left(H_{0}\right)$} & \multicolumn{4}{|c|}{-137.626} & \multicolumn{4}{|c|}{-136.480} \\
\hline \multicolumn{2}{|c|}{$\operatorname{chi}-\operatorname{Square}\left(\chi^{2}\right)$} & \multicolumn{4}{|c|}{30.240} & \multicolumn{4}{|c|}{40.867} \\
\hline \multicolumn{2}{|c|}{$p r>\chi^{2}$} & \multicolumn{4}{|c|}{0.00004} & \multicolumn{4}{|c|}{0.0000003} \\
\hline \multicolumn{2}{|c|}{$A I C$} & \multicolumn{4}{|c|}{286.96} & \multicolumn{4}{|c|}{248.09} \\
\hline
\end{tabular}

(r) Reference group

In addition, the dummy variable that reflect the family preference for eating out is not significant as study result show in table 3 in any model (TSPR and TGPR) that could be explained by known many of restaurants provide delivery services for their costumers by its own or other delivery applications.

The value of test statistics is $\chi^{2}=40.867$ and $\operatorname{pr}\left(\chi_{(6)}^{2}>40.867\right)=0.0000003$, which is less than 0.05 , so we can reject null hypothesis $H_{0}: \beta_{1}=$ $\beta_{2}=\beta_{3}=\beta_{4}=\beta_{51}=\beta_{52}=0$, which indicates that the TGPR model passes the goodness-of-fit test for collected data on the number of times a household consumes FAFH each month.

According to the study results through analyzing the questionnaires of the study sample in the Riyad city, the relationship is positive, which means the increase in the family members may increase the chances go to restaurants. This output might be explained by the high income of Saudi families, especially in the city of Riyadh, and the presence of children in the family may be an incentive to look for entertainment places for them, which markets and restaurants are considered one of the main entertainment elements in Riyadh. This explanation might differ from country to country depend on culture, living cost, and per capita income.

\section{CONCLUSIONS}

This study aimed to analyze variables that affect household demand for FAFH in Riyadh, Saudi Arabia. The demand was measured by the number of times that a household dines in restaurants each month. This number was between one and four times, according the study sample, which followed the Poisson distribution. TSPR and TGPR were applied using five independent variables that represented household income, number of household members, education level of household leader, household preference for restaurant meals, and attraction factors for eating in a restaurant. An analysis of the data showed the following results:

- TGPR is the most significant model to estimate variable coefficients for household demand for restaurant meals.

- Household income as a quantitative economic variable and the number of household members as a quantitative demographic variable are the most important variables in household demand for FAFH. However, the effect of income is more significant than that of the number of household members.

- The reasons that a household may want to eat in a restaurant are important specific variables in the household's demand for FAFH. This study investigated three factors that attract families to a 
particular restaurant: good price, delicious taste, and cleanliness. It was found that good price and delicious taste are the most important, but the effect of choosing a restaurant for good prices is more valuable and more significant than food taste and cleanliness.

- An increase in household income could lead to an increase in household demand for FAFH, so the restaurants may achieve more returns.

\section{RECOMMENDATION}

As this study investigated the impact of socioeconomic and demographic factors on food away from home (FAFH) demand in Riyadh such as household income, number of household members, education level, prices and cleanness of restaurant, and taste of food. Still there are other variables could be used as potential variables could affect FAFH demand in Saudi Arabia in future research such as the change in number of working women which there is shift in the number of female workers recently. The future studies could look at the differences in socio-economic between consumers for different types of restaurants such as traditional, fast food, fish, and luxury restaurants.

Due to the high demand for restaurant meals, officials should tighten the health control and close restaurants that do not comply with health requirements as well security and safety requirements. Restaurants should pay attention to improving the quality of meals and offering them at affordable prices to consumers. The study also recommends raising family awareness, through awareness-raising programs aimed at family members, to rationalize their consumption that leads to providing money for a better life, and to work to raise their health culture through guidelines for the quality of healthy meals and useful to support research and studies that urge to modify the consumption pattern of money families .

\section{ACKNOWLEDGEMENTS}

The authors would like to acknowledge the Deanship of Scientific Research at King Saud University through the College of Food and Agricultural Sciences-Research Center for funding this work. The authors are also grateful to the Deanship of Scientific Research at King Saud University for their technical support.

\section{REFERENCES}

Adams J., Goffe L., Brown T., Lake A.A., Summerbell C., White M. and Adamson A.J., 2015. Frequency and socio-demographic correlates of eating meals out and take-away meals at home: Cross-sectional analysis of the UK national diet and nutrition survey, waves 1-4 (2008-12). Int J. Behav. Nutr. Phys. Act. 1251, pp. 1-9, DOI 10.1186/s12966-015-0210-8.

Akaike H., 1973. Information Theory and an Extension of the Maximum Likelihood Principle. In B. N. Petrov, \& F. Csaki (Eds.), Proceedings of the 2nd International Symposium on Information Theory (pp. 267-281). Budapest: Akademiai Kiado.

Consul P.C. and Jain G.C. 1973. A generalization of the Poisson distribution. Technometrics. 15(4), 791-799.

Cupak A., Pokrivcak J. and Rizov M. 2016. Demand for food away from home in Slovakia. Finance a úvěr: Czech J. Econ and Finance. 66(4), 354-369.

Famoye F. 1993. Restricted generalized Poisson regression model. Commun. Stat. Theory Methods. 22(5), 1335-1354.

Greene W.H. 2003. Econometric Analysis: $5^{\text {th }}$ edition, Pearson Education Inc. New York University, (Ch 21, pp. 212-220). Pearson Education India.

Kim T.H., Lee E.K. and Han E. 2014. Food away from home and body mass outcomes: Taking heterogeneity into account enhances quality of results. Nutrition. 30(9), 1015-1021.

Langellier B.A. 2015. Consumption and expenditure on food prepared away from home among Mexican adults in 2006. Salud Pública de México. 57(1), 4-13.

Liu H., Wahl T.I., Seale Jr., J.L. and Bai, J., 2015. Household composition, income, and food-away-from-home expenditure in urban China. Food Policy. 51, 97-103.

Liu M., Kasteridis P. and Yen S.T. 2013. Breakfast, lunch, and dinner expenditures away from home in the United States. Food Policy. 38, 156-164.

Llanaj E., Ádány R., Lachat C. and D'Haese M. 2018. Examining food intake and eating out of home patterns among university students. PloS One. 13(10), 1-14.

https://doi.org/10.1371/ journal.pone.0197874.

Mutlu S. and Gracia A. 2006. Spanish food expenditure away from home (FAFH): by type of meal. Applied Economics, 38(9), 1037-1047. 

Arabia: a right-left truncated generalized poisson regression model

Queiroz, P., Coelho, A.B., 2018. Food away from home in Brazil: The role of sociodemographic factors and household structure. Int. J. Soc. Econ. 46(4), 503-522.

Richards T.J. and Mancino L. 2013. Demand for food-away-from-home: A multiple-discretecontinuous extreme value model. Eur. Rev. Agric. Econ. 41(1), 111-133.

Tan A.K.G. 2010. Demand for food-away-fromhome in Malaysia: A sample selection analysis by ethnicity and gender. J. Foodservice Bus. Res. 13 (3), 252-267.
The General Authority for Statistics, 2007-2017. Enumerating establishments. Saudi Arabia, Riyadh. https://www.stats.gov.sa/en.

Thompson O.M., Ballew C., Resnicow K., Must A., Bandini L.G., Cyr H.D. W.H. and Dietz W.H. 2004. Food purchased away from home as a predictor of change in BMI z-score among girls. Inter. J. Obes., 28(2), 282-289.

Todd J.E., Mancino L. and Lin B.H. 2010. The impact of food away from home on adult diet quality. USDA-ERS Economic Research Report Paper, (90), 1-18. 


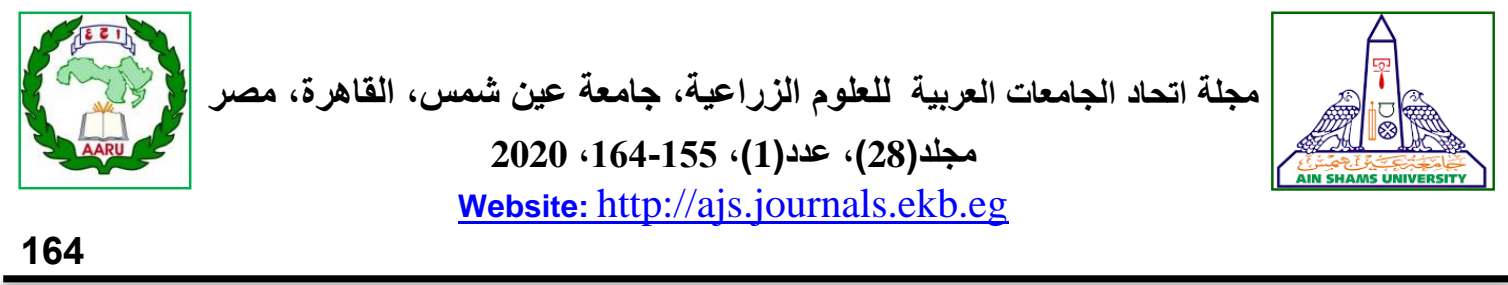

تحليل الطلب العائلي على الوجبات السريعة في مدينة الرياض، بالسعودية: تطبيق نموذج

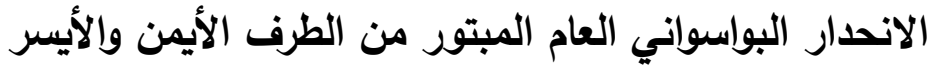

$[10]$

\author{
محمد عبداللطيف النفيسه" - محمود محمد الاريني- علاء أحمد قطب- شرف الاين بكري أحمد

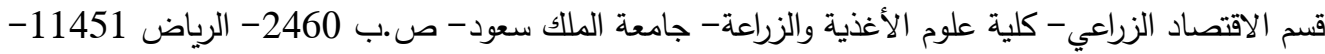

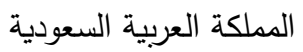

*Corresponding author: malnafissa@ksu.edu.sa

Received 28 January, 2020

Accepted 18 May, 2020

مرات الطلب العائلي (FAFH) خلال الشهر بنسبة

11\% بالرغم أن هذه الدراسة تتاولت تأثير العوامل

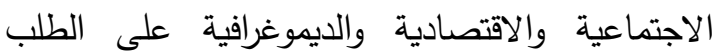

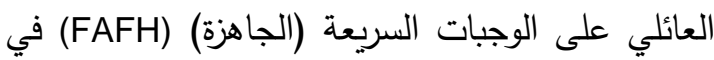

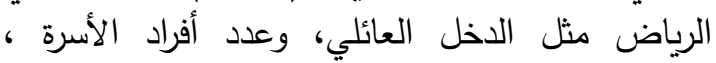

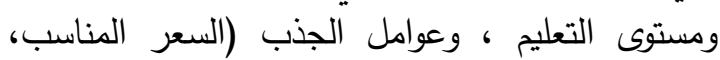

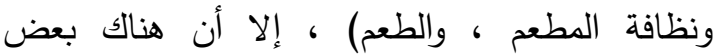

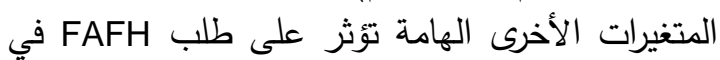

المملكة العربية السعودية يمكن أخذها بعين الاعتبار

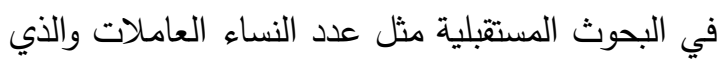

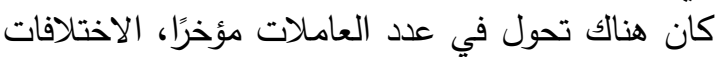
الاجتماعية والاقتصادية بين المستهلكين لأنواع مختلفة

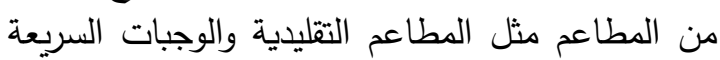
والأسماك والمطاعم الفاخرة. نظرًا لارتفاع الطلب على الطي

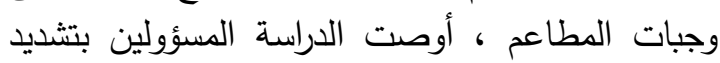

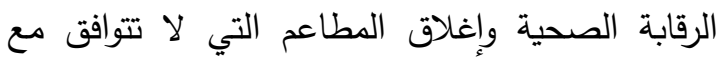
المتطلبات الصحية وكذلك متطلبات الأمن والسلامة،

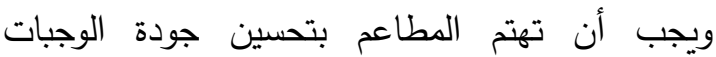
وتقديمها بأسعار معقولة للمستهلكين.

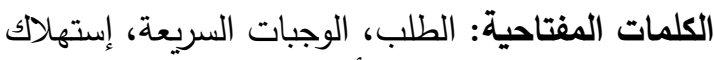
الغذاء، البوتسواني المعدم، أقصى احتمال الطوجات الصرية
الموجـــز

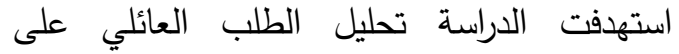

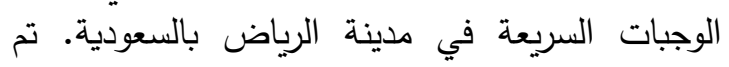
قياس الطلب بعدد مرات طلب الأسرة للوجبات الجاهزة بالبعات

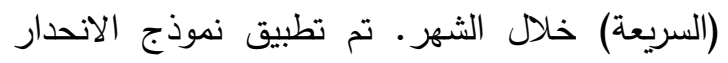

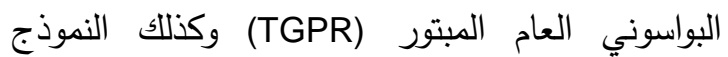
العادي المبتور (TSPR) على بيانات عينة عشوائية حجمها 101 أسرة. تم استخدام طريقة الإمكانية العظمى (ML) في الحصول على نتائج تقديرات معالم

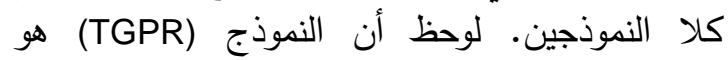

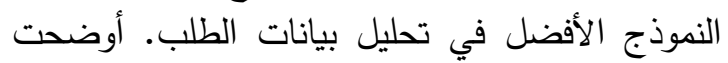
النتائج أن كل من الدخل العائلي وعدد أفراد الأسرة كمتغيرين كميين مستقلين لها أثر معنوي على الثى الطلب،

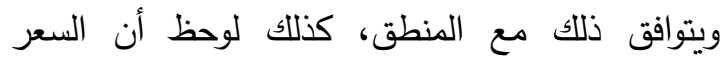

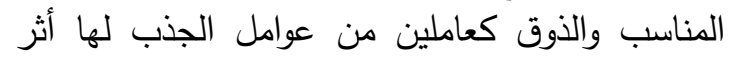
معنوي إيجابي على الطلب العائلي. لوحظ أن أن الدخل كمتغير اقتصادي، وعدد أفراد الأسرة كمتغير ديموجرافي لئي

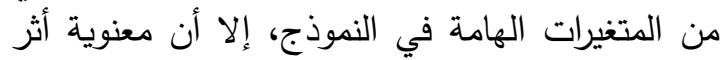

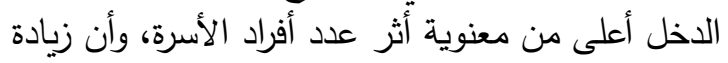

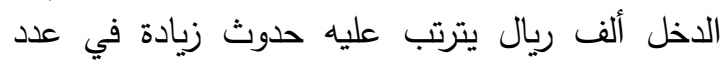

تحكيم: ا.د سميــر القطـانـــــي

ا. ا.د مبحي محمد إسماعيل

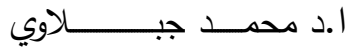

